\title{
Descriptive Study on Socio-Demographic and Risk factors Associated with the Oral Cancers, Batticaloa District
}

\author{
Jasotharan $\mathbf{V}^{1^{*}}$, Beumy Saluja $\mathbf{N}^{1}$, Fathima Nahthiya $\mathrm{FH}^{1}$, Arulanandem $\mathbf{K}^{2}$, Parthiepan $\mathbf{A}^{3}$ and Pirasath $\mathbf{S}^{4}$ \\ ${ }^{1}$ Department of Primary Health Care Sciences, University of Sri Lanka \\ ${ }^{2}$ Department of Primary Health Care Sciences, Faculty of Health Care Sciences, Eastern University of Sri Lanka \\ ${ }^{3}$ Onco Surgeon, Teaching Hospital, Batticaloa, Sri Lanka \\ ${ }^{4}$ Medical Officer, Teaching Hospital, Batticaloa, Sri Lanka
}

*Corresponding author: Vellapody Jasotharan, Medical Student, Faculty of Health Care Sciences, Eastern University of Sri Lanka, Sri Lanka, Tel: 0778315938; E-mail: svjasotharan@gmail.com

Rec date: 2014-02-17, Acc date: 2014-04-26, Pub date: 2014-05-05

Copyright: @ 2014 Jasotharan V. This is an open-access article distributed under the terms of the Creative Commons Attribution License, which permits unrestricted use, distribution, and reproduction in any medium, provided the original author and source are credited.

\begin{abstract}
Objective: Sri Lanka has the highest reported incidence of oral cancer in the world. The aim of the study to investigate the relationship of risk factors with oral cancers.

Materials \& Methods: 596 individuals of Batticaloa district were investigated for this study through intervieweradministrated questionnaire within the time frame for the data collection, applying multi stage cluster sampling technique.

Results \&Discussion: Out of these 596, 63.42\% (Nos. 378) are males. $2 \%$ (Nos. 11) of the people interviewed have been reported with oral cancer. $91 \%$ (Nos. 10) of the total number of oral cancer victims are from rural area. $63.64 \%$ (Nos. 7) are in the range of $61-75$ years of age among oral cancer. There has no imply any clue about coalition between sex and oral cancer. $30.20 \%$ (Nos. 180) have the habit of Tobacco consumption and of which only $5 \%$ (Nos. 7) were identified with oral cancer. Chewing is popular method $[77.78 \%$ (Nos. 7)] among oral cancer victims. $32.38 \%$ (Nos. 193) are having the habit of chewing beetle. $81.82 \%$ (Nos. 9) oral cancer patients have the habit of chewing beetle. $90.67 \%$ (Nos. 175) people use one or more other substances such as slake lime, areca nut and Tobacco together. $66.67 \%$ (Nos. 6) oral cancer patients have the same practice of chewing while sleeping in the night. It is noted that $100 \%$ (Nos. 6) of the people with oral cancer and who are beetle chewers while sleeping in the night, keep the beetle pulp near their molar. $32.21 \%$ (Nos. 192) people including 3 (27.27\%) out of 11 oral cancer victims are having the habit of consuming Alcohol.
\end{abstract}

Conclusions: Oral cancers are common among people aged 61-75 years. Tobacco consumption and Beetle chewing are most inducing factors of oral cancer.

Keywords: Oral cancers; Batticaloa; Risk factors

\section{Introduction}

The incidence of oral cavity and pharyngeal cancer has shown increasing trend worldwide, as have the mortality rate for patients with these malignancies [1]. Oral cavity cancer is one of the 10 most frequent cancers globally [2]. Oral cancer is currently a major global health issue.

Sri Lanka has the highest reported incidence of oral cancer in the world [3], Oral and pharyngeal cancers constitute the most common cancer for Sri Lankan men and ranks fourth for women [4]. The prevalence of risk factors associated with oral cancer is reportedly high [5].

The actual cause for oral cancer is not known. However there are many factors which are commonly associated with oral cancer. Tobacco smoking, alcoholic consumption, betel quid chewing, poor oral health, and human papilloma virus infection. Therefore, primary prevention such as cessation of tobacco smoking and alcohols drinking along with early detection is necessary control procedures to improve the prognosis of oral cancer.
However, few prospective cohort studies for the risk factors of developing oral cancer have been performed in Sri Lana. However, no studies have been performed to find out the Sociodemographic factors and risk factors associated with the oral cancers in Batticaloa District.

Therefore, this study aimed to investigate the relationship between smoking, alcoholic consumption, and betel quid chewing and oral cancers in a prospective manner as well as prevalence and sociodemographic factors associated with the oral cancers.

\section{Materials \& Methods}

\section{Study design}

Descriptive cross sectional study

\section{Study area}

Batticaloa District

\section{Study Population}

Oral cancer patients living in Batticaloa District 
Citation: Jasotharan V, Beumy Saluja N, Fathima Nahthiya FH, Arulanandem K, Pirasath S, et al. (2014) Descriptive Study on Socio-Demographic and Risk factors Associated with the Oral Cancers, Batticaloa District. J Blood Disorders Transf 5: 1000216. doi: $10.4172 / 2155-9864.1000216$

Page 2 of 6

\section{Study period}

12 months

\section{Sampling procedure and sample size}

Multistage Cluster sampling method will be used to obtain the samples in our study. All divisional secretiat will be selected among Batticaloa District and three gramma secretiat divisions will be selected among each divisional secretiat. Twenty five families will be selected among the each gramma secretiat divisions in right handed manner in a particular place of arrival. One family member except aged less than 16 years will be selected among the each family with lottery method.

\section{Exclusion criteria}

All the family members aged less than 16 years among the selected families will be excluded from this study.

\section{Instruments for data collection}

Interviews based predesigned questionnaires.

\section{Ethical clearance}

Ethical clearance of the study will be obtained from Ethical Review Committee, Faculty of Health Care Sciences, and Eastern University of Sri Lanka.

\section{Statistical Analysis}

All data were analyzed by using SPSS analytical package.

\section{Results \& Discussion}

Total of 596 individuals of Batticaloa district were investigated for this study through interviewer-administrated questionnaire within the time frame for the data collection, applying multi stage cluster sampling technique.

Out of these 596 samples $55.70 \%$ (Nos. 332) and 44.30\% (Nos. 264) represent rural and urban areas respectively. Also, 63.42\% (Nos. 378) of the people included in the study are male and $36.58 \%$ (Nos. 218) are female. The sample selected for this study consists of different ethnic groups living in the district.

During the study, 2\% (Nos. 11) of the people interviewed have been reported with oral cancer in Batticaloa District. The incidence of oral cavity and pharyngeal cancer has shown increasing trend worldwide However, Sri Lanka has the highest reported incidence of oral cancer in the world [3].

The Figure 1 shows ethnic breakdown of the interviewee of the study.

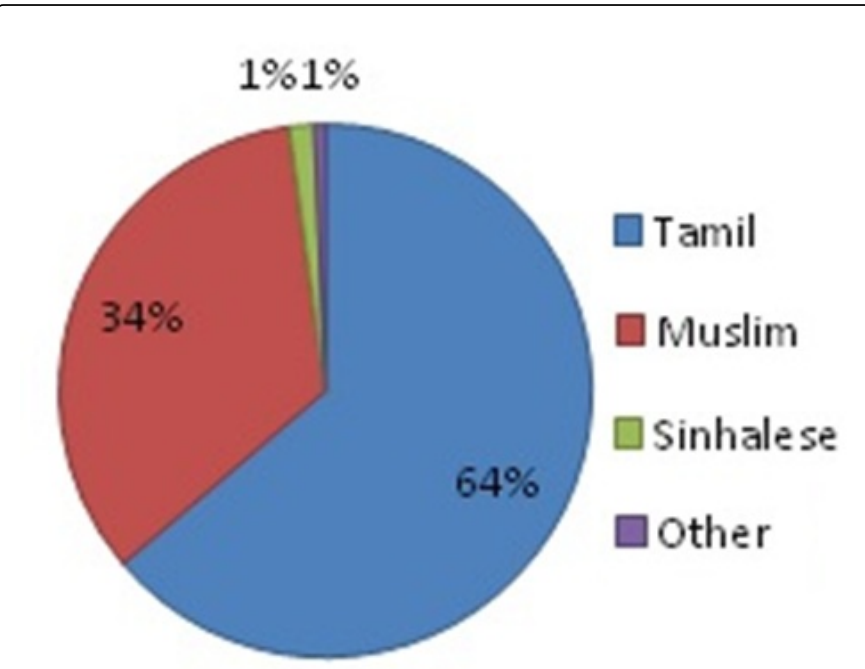

Figure 1: Ethnic Breakdown of the interviewee of the study.

As the main objective of the study is to identify the risk factors for the oral cancer, the following section describes the results of this study based on some statistics according to the data collected.

\section{Socio- Demographic Factors}

Socio-Demographic details such as place of residence, age, sex, ethnicity, marital status, education qualification, type of employment and family income of the people were considered to understand their relationship with the oral cancer.

\section{Place of Residence}

The study found that $91 \%$ (Nos. 10) of the total number of oral cancer victims are from rural and only 9\% (Nos. 1) are from urban. The chi-squared test statistic $\chi^{\wedge} 2(\mathrm{DF}=1, \mathrm{~N}=596)=5.63$ with associated $\mathrm{p}$-value $<0.018$ confirms that there is a strong association between place of residence and the condition of the people whether normal or with oral cancer.

\section{Age}

Among the people with oral cancer, 63.64\% (Nos. 7) are in the range of $61-75$ years of age and the remaining $36.36 \%$ (Nos. 4) are falling into the age range of 46-60 years. The chi-squared test to ensure whether any age group of people are more likely to oral cancer indicates that there is significant relationship between the different age group and their condition $\left(\chi^{2}(\mathrm{DF}=3, \mathrm{~N}=596)=31.44\right.$ and $\mathrm{p}$ value $<0.0001)$. Examining the pattern of prevalence, it is noted that the age group of 61-75 years has more chance of having oral cancer. However, the age group of 46-60 years also has relatively higher risk of oral cancer. The Figure 2 illustrates the pattern of different age category and condition of the people taken for the study. Oral cancer most commonly occurs in middle-aged and older individuals, although a disturbing number of these malignancies is also being documented in younger adults in recent years [6] 
Citation: Jasotharan V, Beumy Saluja N, Fathima Nahthiya FH, Arulanandem K, Pirasath S, et al. (2014) Descriptive Study on Socio-Demographic and Risk factors Associated with the Oral Cancers, Batticaloa District. J Blood Disorders Transf 5: 1000216. doi: $10.4172 / 2155-9864.1000216$

Page 3 of 6

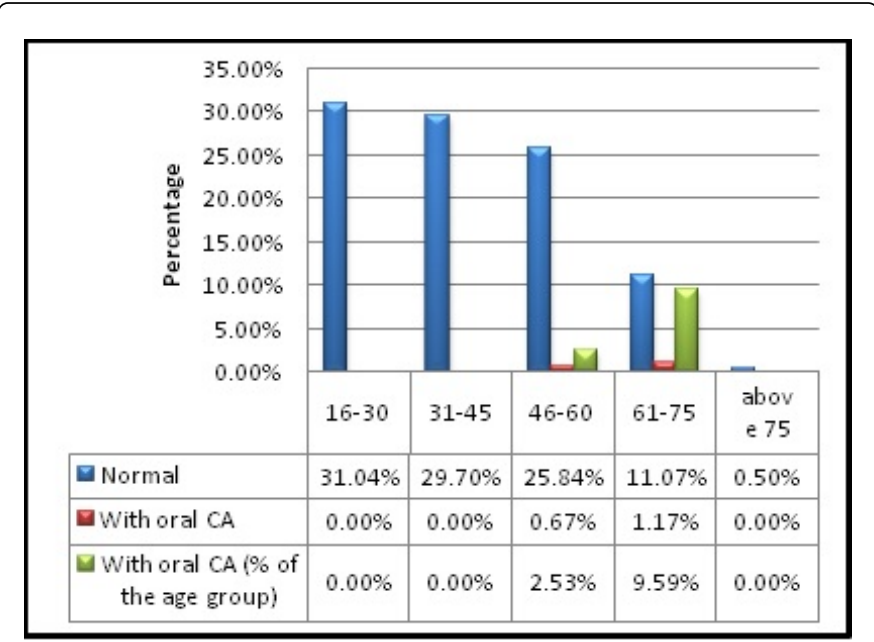

Figure 2: Pattern of different age category and condition of the people taken for the study.

\section{Gender}

The difference between the percentages of male and female with oral cancer is only around $10 \%$. This figure does not imply any clue about coalition between sex and oral cancer. Intraoral and oropharyngeal tumors are more common among men than women, with a male: female ratio of over 2:1 [7-9] in recent studies in world. Also, the Chi-squared test statistic is $1.66(\mathrm{DF}=1, \mathrm{~N}=596)$ with associated p-value 0.21 . Thus, a conclusion can be made that there is no any effect of sex in triggering oral cancer. But, oral cancer represents approximately three percent of all malignancies in men and two percent of all malignancies in women in the United States. It is estimated that these tumors will account for 28,900 new cases and 7,400 deaths in 2002 in the United States [3].

\section{Ethnicity}

Out of the 11 people reported with oral cancer during the study, 90.91\% (Nos. 10) are Tamils and only a 9.09\% (Nos. 1) are Muslim. Also, no person from other ethnic group was identified with oral cancer. Interestingly, the Chi-squared test statistic for ethnicity over the condition of the people does not prove that any ethnic group is prone to the disease $\left(\chi^{2}(\mathrm{DF}=3, \mathrm{~N}=596)=3.59\right.$ with $\mathrm{p}$-value $\left.=0.31\right)$.

\section{Marital Status}

All the oral cancer patients identified during the study are either married or widow. However, the Chi- squared statistic guarantees that there is no relationship between marital status and oral cancer $\left(\chi^{2}(\mathrm{DF}=3, \mathrm{~N}=596)=4.86\right.$ with $\mathrm{p}$ value $=0.18$ ).

\section{Education Qualification}

$45.45 \%$ of the oral cancer patients identified during the study have never gone to school and $27.27 \%$ of the same belong to the category of school education from grade 1 to
5.The Chi-squared test statistic $\left(\chi^{2}(\mathrm{DF}=7, \mathrm{~N}=596)=22.78\right.$ with $\mathrm{p}$-value $=\mathbf{0 . 0 0 2 8}$ ) also validate the hypothesis that there is an association between level of education and the prevalence of oral cancer.

\section{Employment}

The study had covered different occupational groups. Among the people met during the study, $36.24 \%$ (Nos. 216) were unemployed. Out of eleven people with oral cancer, $63.64 \%$ (Nos. 7) are unemployed.

However, the Chi-squared statistic $\left(\chi^{2}(\mathrm{DF}=4, \mathrm{~N}=596)=4.41\right.$ with p-value $=0.35)$ does not show any linkage between type of employment and oral cancer.

\section{Family Income \& Oral Cancer}

$63.64 \%$ (Nos. 7) of the people with oral cancer came across during the study are getting monthly income below Rs.5, 000. The Chisquared statistic $\left(\chi^{2}(\mathrm{DF}=4, \mathrm{~N}=596)=17.11\right.$ with $\mathrm{p}$-value $\left.<0.002\right)$ in dicates that there is a significant association between family income and oral cancer. Thought this result seems contradictory to the previous result that the employment and oral cancer are not associated, in fact this may be of the reason that the person interviewed is an unemployed but the total family income may be more by means of some other income sources.

If we look into this result little deeply, we may postulate that low income might have affected the life style and attitude of the people in some way and that might have resulted in oral cancer.

\section{Risk Factors}

The actual cause for oral cancer is not known. However there are many factors which are commonly associated with oral cancer. Tobacco smoking and betel quid chewing are found to be associated with oral cancers than alcoholic consumption in this study.

\section{Tobacco Consumption Habits}

Among the people met during the study, $30.20 \%$ (Nos. 180) have the habit of Tobacco consumption and of which only $5 \%$ (Nos. 7) were identified with oral cancer. However, the Chi squared test performed to understand the effect of Tobacco consumption makes clear that there is a significant relationship between Tobacco consumption and oral cancer $\left(\chi^{2}(\mathrm{DF}=1, \mathrm{~N}=596)=14.16\right.$ with $\mathrm{p}$ value $=0.0002$ ).

The strong association between cancers of the oral cavity and pharynx with tobacco use is well established. Epidemiological studies show that the risk of developing oral cancer is five to nine times greater for smokers than for nonsmokers [9-12].

$44.44 \%$ (Nos. 4) of the Tobacco consumers with oral cancer are having this habit for more than 20 years. The Figure 3 shows duration and percentage of Tobacco consumers who are with oral cancer. 
Citation: Jasotharan V, Beumy Saluja N, Fathima Nahthiya FH, Arulanandem K, Pirasath S, et al. (2014) Descriptive Study on Socio-Demographic and Risk factors Associated with the Oral Cancers, Batticaloa District. J Blood Disorders Transf 5: 1000216. doi: $10.4172 / 2155-9864.1000216$

Page 4 of 6

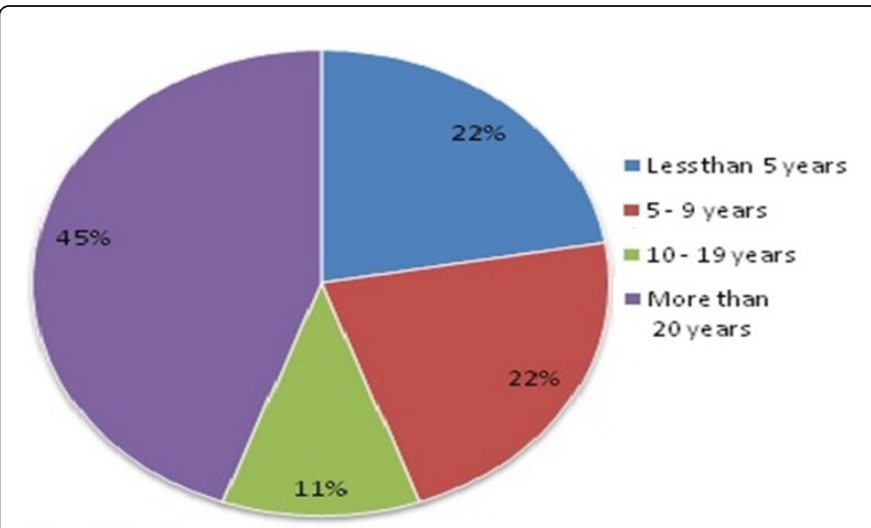

Figure 3: Duration and percentage of Tobacco consumers who are with oral cancer

But the Chi- squared test does not prove that there is an association between period of habits and the condition of the people $\left(\chi^{2}(\mathrm{DF}=3\right.$, $\mathrm{N}=180)=4.88$ with $\mathrm{p}$-value $=0.18)$. Out of 9 people who are having oral cancer and with the habit of Tobacco consumption, $88.89 \%$ (Nos. 8) are consuming Tobacco less than 10 times per day and only $11.11 \%$ (Nos. 1) are using 10 to 20 times per day. The Chi-squared statistic $\left(\chi^{2}\right.$ $(\mathrm{DF}=2, \mathrm{~N}=180)=7.80$ with $\mathrm{p}$-value $<0.02)$ shows that there is a relationship between the frequency of the habit per day and condition of the people.

Out of the subject, $81.82 \%$ (Nos. 9) have the habit of Tobacco consumption and of which $77.78 \%$ (Nos. 7) are consuming by the method of chewing, $11.11 \%$ (Nos. 1) are smoking and the remaining $11.11 \%$ (Nos. 1) are by both chewing and smoking. $18.18 \%$ (Nos. 2) of the people with oral cancer investigated never have the habit of Tobacco consumption. In addition to these figures, The Chi squared test statistic indicates method of consumption of Tobacco is somewhat related to condition of people $\left(\chi^{2}(\mathrm{DF}=3, \mathrm{~N}=180)=8.52\right.$ with $\mathrm{p}$-value $<$ 0.04).

Marijuana use is also considered to be a potential risk factor and may be partly responsible for the rise in oral cancers seen among young adults $[13,14]$. However, further epidemiological studies are necessary to confirm the purported association of marijuana and oral cancer in younger patients $[15,16]$. However there was no cases reported in our study. Snuff and chewing tobacco have also been associated with an increased risk for oral Cancer [17].

In one study of women in the southern United States, chronic users of snuff were estimated to have a four times greater risk of developing oral cancer [18]. The incidence of oral cancer in West Virginia is below the national average, even though this state has the highest consumption of chewing tobacco in the United States [19].

\section{Beetle Chewing Habits}

Among the people surveyed for this study, $32.38 \%$ (Nos. 193) are having the habit of chewing beetle and $0.84 \%$ (Nos. 5) has stopped the habit for last 6 months. Out 11 people with oral cancer 81.82\% (Nos. 9) have the habit of chewing beetle and the remaining $18.18 \%$ (Nos. 2) nerve have the habit. The analysis shows that habits of chewing beetle are significantly associated with the condition of the people $\left(\chi^{2}\right.$ test statisitc $(\mathrm{DF}=2, \mathrm{~N}=596)=12.52$ with $\mathrm{p}$-value $<0.002)$. In India and
Southeast Asia, the chronic use of betel quid (paan) in the mouth has been strongly associated with an increased risk for oral cancer [20].

The test to know whether period of beetle chewing habits influences the condition of the people reveals that there is a relationship between them $\left(\chi^{2}\right.$ test statisitc $(D F=3, N=596)=13.57$ with $p$-value $\left.<0.004\right)$. Also, the study points out that the frequency of the habit per day is also related to the condition of the people $\left(\chi^{2}\right.$ test statisitc (DF $=3, \mathrm{~N}=596)=12.02$ with $\mathrm{p}$-value $<0.007)$.

Out of 193 beetle chewers, 90.67\% (Nos. 175) people use one or more other substances such as slake lime, areca nut and Tobacco together. $65.14 \%$ (Nos. 114) of this category use all three types of substances while chewing beetle. It is noted that all 9 people who are beetle chewers and having oral cancer are using these three substances with beetle. The quid typically consists of a betel leaf that is wrapped around a mixture of areca nut and slaked lime, usually with tobacco and sometimes with sweeteners and condiments [20].

Also, 31.61\% (Nos. 61) of the people with the habit of beetle chewing are having the custom of chewing beetle while sleeping in the night. Regarding to the people who are beetle chewers and with oral cancer, $66.67 \%$ (Nos. 6), have the same practice of chewing while sleeping in the night. The slaked lime results in the release of an alkaloid from the areca nut, which produces a feeling of euphoria and well-being in the user. The statistical analysis shows that practice of chewing while sleeping in the night and condition of the people are associated $\left(\chi^{2}\right.$ test statisitc $(\mathrm{DF}=1, \mathrm{~N}=193)=5.37$ with $\mathrm{p}$-value $\left.=0.021\right)$. In addition, $54.10 \%$ (Nos. 33) of the people with the practice of chewing while sleeping in the night keep beetle pulp near their molar and the remaining $45.90 \%$ (Nos. 13) keep the same under their tongue. It is again noted that $100 \%$ (Nos. 6) of the people with oral cancer and who are beetle chewers while sleeping in the night, keep the beetle pulp near their molar. As a consequent of the previous result the statistical test gives a clear indication for an association between oral cancer and the place of keeping the beetle mixture ( $\chi^{2}$ test statisitc (DF $=1, \mathrm{~N}=61)=5.65$ with $\mathrm{p}$-value $=0.017)$. The Figure 4 illustrates the comparison between beetle chewing habit while sleeping and oral cancer victims.

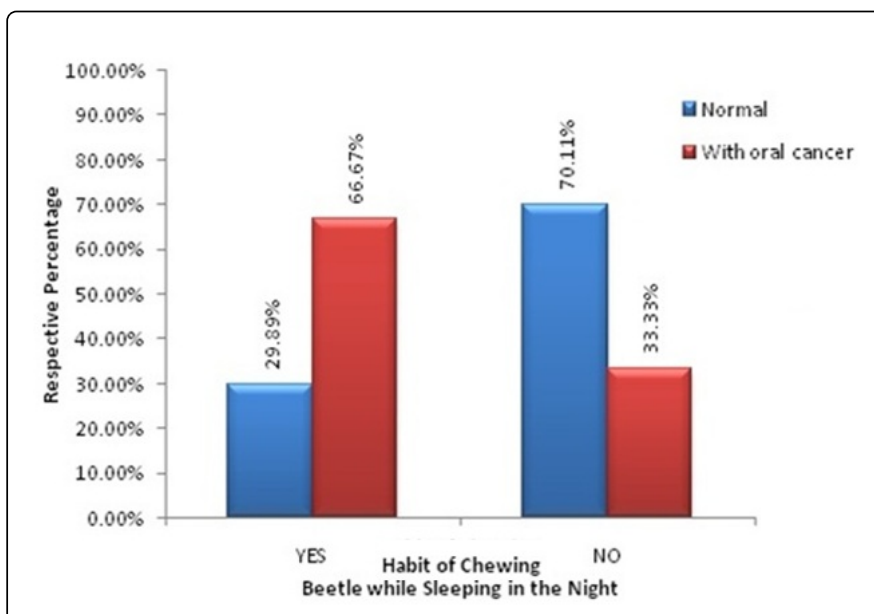

Figure 4: Comparisons between beetle chewing habit while sleeping and oral cancer victims.

Regarding the awareness about the risk factors and oral cancer, $74.33 \%$ (Nos. 443 ) of the people investigated for this study are having 
Citation: Jasotharan V, Beumy Saluja N, Fathima Nahthiya FH, Arulanandem K, Pirasath S, et al. (2014) Descriptive Study on Socio-Demographic and Risk factors Associated with the Oral Cancers, Batticaloa District. J Blood Disorders Transf 5: 1000216. doi: $10.4172 / 2155-9864.1000216$

Page 5 of 6

knowledge on oral cancer and their causes. But 54.55\% (Nos. 6) out of 11 people identified with oral cancer are not aware about oral cancer and their risk factors. The statistical analysis performed reveals that there is an association between public's awareness about oral cancer and condition of the people $\left(\chi^{2}\right.$ test statisitc $(D F=1, N=596)=4.90$ with p-value< 0.027).

\section{Alcohol Consumption Habits}

Alcohol use has been identified as a major risk factor for cancers of the upper aero digestive tract $[16,17]$. Among the people investigated during the study, 32.21\% (Nos. 192) people including 3 (27.27\%) out of 11 oral cancer victims are having the habit of consuming Alcohol. 137 (71.35\%), 25(13.02\%), 18(9.38\%) and 12(6.25\%) out of 192 Alcohol consumers are addicted to the habit for less than 5 years, 5 to 9 years, 10 to 19 years and more than 20 years respectively. The Chisquared statistical analysis performed to understand the effect of Alcohol consumption habit and condition of the people does not indicate any association $\left(\chi^{2}\right.$ test statisitc $(\mathrm{DF}=1, \mathrm{~N}=596)=0.13$ with $\mathrm{p}$ value $=0.723$ ). Thus, the other factors such as type of the liquor, frequency of the habit per day and duration of the habit also do not interrelate to the condition of the people according to the data obtained for this study. In studies controlled for smoking, moderateto-heavy drinkers have been shown to have a three to nine times greater risk of developing oral cancer $[16,17]$.

\section{Interaction between Risk Factors}

In addition to the analysis of the risk factors individually, the test including the interaction between these 3 risk factors leads to make some conclusion that there is a significant association between combinations of risk factors and the condition of the people. $\left(\chi^{2}\right.$ test statisitc $(\mathrm{DF}=7, \mathrm{~N}=596)=30.17$ with $\mathrm{p}$-value $=0.0001)$. Also, it is noted that $6(54.55 \%)$ people out 11 oral cancer patients investigated having the habit of both Tobacco consumption and Beetle chewing while 3 $(27.27 \%)$ with oral cancer are having all the three habits mentioned above. Examining the figures, we can draw a conclusion that the habits of both the Tobacco consumption and Beetle chewing are most inducing factors of oral cancer than Alcohol consumption. The following Venn-Diagram illustrates different habits, corresponding percentage of the people with the habit and percentage of the people with oral cancer among the region (within square brackets).

\section{Summary of results of the study}

The conclusion of this study is given in the following tabular form, examining the pattern of the frequencies and according to the results of statistical test performed to the data collected (Table 4.1).

\section{Conclusions}

Based on 596 individuals (Normal healthy individuals: Oral cancer victims $=585: 11$ ) of Batticaloa district were investigated for this study through interviewer-administrated questionnaire within the time frame for the data collection, applying multi stage cluster sampling technique, The following are important conclusions;

Oral cancers are common among people aged 61-75 years with low level of education and low family income from rural area and no association with gender distribution.
Oral cancers are significantly associated with habit of tobacco consumption and beetle chewing. However alcohol is not associated with oral cancers.

Tobacco consumption included frequency (at least $<10 /$ day or more) and type (at least chewing) are significantly associated with oral cancers and duration is not associated with oral cancers.

Habit of betel chewing included frequency (at least $<10 /$ day or more), duration (at least 5-9 years), with added substances (slake lime, areca nut and tobacco), habit while sleeping in the night and place of keeping beetle mixture while sleeping near molar area are significantly associated with oral cancers. Low awareness of habit of betel chewing causing oral cancer is related to predisposition to oral cancers.

Examining the figures, we can draw a conclusion that the habits of both the Tobacco consumption and Beetle chewing are most inducing factors of oral cancer than Alcohol consumption.

However, there are some limitations in our study; sampling size is small. Further Large scale studies; large sampling size are necessary to draw attention of socio demographic and risk factors associated with oral cancers in Batticaloa District.

\section{References}

1. Blot WJ, McLaughlin JK, Devesa SS, et al (1994). Oral and pharyngeal cancers. In: Schottenfeld D, Fraumeni, JF (Eds.), Cancer Epidemiology and Prevention(2nd Edn.),WB Saunders, Philadelphia.

2. Parkin DM, Pisani P, Ferlay J (1993) Estimates of the worldwide incidence of eighteen major cancers in 1985. Int J Cancer 54: 594-606.

3. American Cancer Society merican Cancer Society (2002) Cancer facts and figures. Atlanta, GA.

4. Neville BW, Damm DD, Allen CM, et al. (2002) Oral\& maxillofacial pathology (3rd Edn.), Saunders, P. 337-369.

5. Sun X1, Tong LP, Wang YT, Wu YX, Sheng HS, et al. (2011) Can global variation of nasopharynx cancer be retrieved from the combined analyses of IARC Cancer Information (CIN) databases? PLoS One 6: e22039.

6. National Cancer Control Programme. Cancer incidence 1995 Sri Lanka. NCCP, Colombo, 2002.

7. Warnakulasuriya KAAS (1992) Smoking and chewing habits in Sri Lanka: implications for oral cancer and precancer. In: Gupta PC, Hamner JE, Murti PR(Eds.) Control of tobacco related cancers and other diseases. Oxford University, Bombay, 113-118.

8. Swango PA (1996) Cancers of the oral cavity and pharynx in the United States: an epidemiologic overview. J Public Health Dent 56: 309-318.

9. Ries LAG, Hankey BF, Miller BA, (1991) CancerStatistics Review 1973-1988. National Cancer Institute, NIH Publication No. 91-2789.

10. Silverman S Jr, Shillitoe EF (1998) Etiology and Predisposing Factors. In: Silverman S Jr (Edr.) Oral Cancer.(5th Edn.), BC Decker Inc, Hamilton, Ontario, Canada, P. 7-24.

11. Goldberg HI, Lockwood SA, Wyatt SW, Crossett LS (1994) Trends and differentials in mortality from cancers of the oral cavity and pharynx in the United States, 1973-1987. Cancer 74: 565-572.

12. Caplan DJ, Hertz-Picciotto I (1998) Racial differences in survival of oral and pharyngeal cancer patients in North Carolina. J Public Health Dent 58: 36-43.

13. Mashberg A, Boffetta P, Winkelman R, Garfinkel L (1993) Tobacco smoking, alcohol drinking, and cancer of the oral cavity and oropharynx among U.S. veterans. Cancer 72: 1369-1375.

14. Jovanovic A, Schulten EA, Kostense PJ, Snow GB, van der Waal I (1993) Tobacco and alcohol related to the anatomical site of oral squamous cell carcinoma. J Oral Pathol Med 22: 459-462. 
Citation: Jasotharan V, Beumy Saluja N, Fathima Nahthiya FH, Arulanandem K, Pirasath S, et al. (2014) Descriptive Study on Socio-Demographic and Risk factors Associated with the Oral Cancers, Batticaloa District. J Blood Disorders Transf 5: 1000216. doi: $10.4172 / 2155-9864.1000216$

Page 6 of 6

15. Andre K, Schraub S, Mercier M, Bontemps P (1995) Role of alcohol and tobacco in the aetiology of head and neck cancer: a case-control study in the Doubs region of France. Eur J Cancer B Oral Oncol 31B: 301-309.

16. Blot WJ, McLaughlin JK, Winn DM, Austin DF, Greenberg RS, et al (1988) Smoking and drinking in relation to oral and pharyngeal cancer. Cancer Res 48: 3282-3287.

17. Lewin F, Norell SE, Johansson H, Gustavsson P, Wennerberg J, et al (1998) Smoking tobacco, oral snuff, and alcohol in the etiology of squamous cell carcinoma of the head and neck: a population-based casereferent study in Sweden. Cancer 82: 1367-1375.
18. Silverman S Jr, Griffith M (1972) Smoking characteristics of patients with oral carcinoma and the risk for second oral primary carcinoma. J Am Dent Assoc 85: 637-640.

19. Zhang ZF, Morgenstern H, Spitz MR, Tashkin DP, Yu GP et al. (1999) Marijuana use and increased risk of squamous cell carcinoma of the head and neck. Cancer Epidemiol Biomarkers Prev 8:1071-1078.

20. Bouquot JE, Meckstroth RL (1998) Oral cancer in a tobacco-chewing US population--no apparent increased incidence or mortality. Oral Surg Oral Med Oral Pathol Oral Radiol Endod 86: 697-706. 